\title{
El cambio climático, ¿una cuestión de fanatismo ecológico?
}

\author{
Amparo Vilches ${ }^{1}$ y Daniel Gil Pérez
}

ABSTRACT (Climatic change, a problem of ecological fanaticism?)

Climatic change has given place to pseudo-scientific debates that demand clarification in order to make possible citizens responsible attitudes and behavior oriented towards the attainment of a culturally plural and physically sustainable development.

KEY WORDS: Science Education for Sustainability, Science versus pseudo-science, Ecologist Movement

\section{Introducción}

Educación Quimica es una de las mejores revistas educativas en el ámbito iberoamericano, con un amplio y solvente Consejo Editorial. Una revista, por otra parte, que ha creado la sección permanente "Educación Química para un futuro sostenible" respondiendo así positivamente al llamamiento de Naciones Unidas para que los educadores de todas las áreas y niveles contribuyamos a formar una ciudadanía consciente de la grave situación de emergencia planetaria a la que la humanidad ha de hacer hoy frente y preparada para participar en la toma de decisiones y la adopción de las medidas correctoras necesarias (www.oei.es/decada).

Con estos antecedentes debemos manifestar la sorpresa inicial que ha supuesto para nosotros la lectura del Editorial del volumen 19, número 2 (Garritz y Arjonilla, 2008), que parece poner en cuestión la fiabilidad de los estudios acerca del cambio climático y otros tópicos ambientales, puesto que se afirma contundentemente "El cambio climático, al igual que los tópicos ambientales que le preceden y acompañan, se ha abordado insistentemente con un discurso de tono religioso que raya el fanatismo ecológico".

En apoyo de esta tesis se incluyen referencias a:

- simples artículos periodísticos, como el de Carlos Wotzkow, publicado en la revista del exilio cubano Guaracabuya, o el de Carmen Pérez-Lanzac, conocida especialista, entre otros, en "La historia del grupo musical La Oreja de Van Gogh”;

- un libro escrito por Jorge Alcalde, periodista de la cadena COPE (expresión de las tesis más fundamentalistas de los obispos españoles);

— un programa de la televisión inglesa ("La gran estafa del calentamiento global") valorado muy negativamente por la comunidad científica por su falta de rigor y tendenciosidad;

- incluso un correo electrónico recibido como spam (mensaje no solicitado).

\footnotetext{
${ }^{1}$ Universitat de València, España.

Recibido: 6 de agosto de 2008; aceptado: 20 de agosto de 2008
}

Todo ello resulta francamente sorprendente en una publicación científica como Educación Química y nos ha hecho sospechar que el Editorial que comentamos sólo tiene sentido como estrategia provocadora para hacer reaccionar a sus numerosos lectores frente a unas tesis "negacionistas" que, pese a carecer de todo fundamento científico, son profusamente difundidas por los medios (aunque ciertamente, no por las revistas científicas), contribuyendo a la confusión de la ciudadanía. Hemos decidido, pues, "recoger el guante" y contribuir a una crítica razonada de dichas tesis, convencidos de que los autores del Editorial nos lo agradecerán y de que ello puede darles pie a un nuevo Editorial clarificador.

\section{¿Un discurso irracional marcado por el fanatismo?}

Centraremos nuestra discusión en la tesis central del Editorial acerca del "tono religioso que raya el fanatismo ecológico" con que se abordan los tópicos ambientales y muy concretamente el cambio climático. Podemos coincidir en que las concepciones expresadas por algunos ciudadanos relevantes (en cualquier campo distinto al de la investigación científica sobre el clima) o el tratamiento que se da a esta problemática en los medios rayan a menudo en lo irracional y no fundamentado científicamente, incurriendo en el fanatismo ecológico... o, tan a menudo o más, en el anti-ecológico. Pero no podemos aceptar - y estamos seguros de que los autores del Editorial tampoco- una crítica genérica a cómo se han abordado los tópicos ambientales por la comunidad científica.

Comentando un artículo publicado en la prestigiosa revista Science hace más de 40 años (White, 1967) el Editorial insiste en esta tesis del carácter religioso del movimiento ecologista y afirma que la ecología humana "estaría profundamente condicionada por nuestras creencias acerca de nuestra esencia y nuestro destino, es decir, por la religión". Como apoyo de esta conclusión se reproducen varios párrafos de dicho artículo, en el más significativo de los cuales podemos leer "...la tecnología moderna debe ser explicada, al menos parcialmente, como el logro de la voluntad del dogma cristiano de la trascendencia del hombre y su justo dominio sobre la naturaleza". Resulta obvio que White no está mostrando aquí el ori- 
gen religioso de las corrientes ecológicas modernas sino, precisamente, de las contrarias, es decir, de aquellas que ven justo el dominio de la especie humana sobre la naturaleza. White, en definitiva, está poniendo de relieve el carácter religioso del movimiento anti-ecologista.

La cuestión está en superar los discursos irracionales —sean ecologistas o anti-ecologistas- y apoyarse en las investigaciones rigurosas y convergentes que han ido conformando el cuerpo de conocimientos hoy aceptado por la comunidad científica acerca de la actual situación de emergencia planetaria y, muy concretamente, del cambio climático (Vilches et al., 2008). No entendemos, pues, por qué el Editorial destaca extensamente las tesis del especialista en ciencias políticas Bjorn Lomborg (2001), uno de los muy escasos representantes que quedan hoy del "negacionismo" - presentados como críticos del "discurso oficial del cambio climático"- y no insiste en el ingente trabajo realizado contracorriente por expertos en muy diversos campos que van de la Biología, la Física o la Química a la Meteorología.

Debemos dejar claro que Lomborg y su escasa compañía no son los Copérnicos o Galileos que se atreven a desafiar los dogmas oficiales con estudios rigurosos. Son, por el contrario, expresión de las tesis y prácticas vigentes que siguen sin querer reconocer los efectos probados de la acción humana sobre el medio y la necesidad de poner límites a una acción auténticamente depredadora puesta al servicio de intereses particulares a corto plazo.

Es la comunidad científica la que ha elaborado un conocimiento considerado "políticamente incorrecto" (incorrecto, por supuesto, a los ojos de las compañías petrolíferas y de todos aquellos que, guiados por intereses miopes, prefieren que no se cuestione el actual sistema productivo, insolidario y literalmente suicida). Recordemos a este respecto la denuncia realizada por James Hansen, director del Instituto Goddard para Estudios Espaciales de la NASA, la agencia espacial estadounidense, y confirmada por otros científicos: Hansen ha mostrado documentadamente que expertos a su cargo y de la Oficina Nacional de Administración Oceánica y Atmosférica (NOAA, por sus siglas en inglés) han sido censurados por el gobierno de los Estados Unidos, impidiendo que llegara al público información sobre el calentamiento planetario.

Como vemos, el "discurso oficial" que se ha tratado de mantener a toda costa y contra toda evidencia, recurriendo incluso a la censura de los resultados científicos, ha sido que no hay cambio climático y que si lo hay tiene un origen natural, no ligado a la quema de combustibles fósiles. Hoy, sin embargo, la abundancia de resultados plenamente convergentes impide que se siga ocultando una realidad que exige intervención urgente, como han expresado el Panel Intergubernamental de Cambio Climático en su IV Informe (IPCC, 2007) y numerosos expertos como, entre otros muchos, el biólogo evolucionista, fisiólogo y biogeógrafo Jared Diamond (2006), profesor en la Universidad de Los Ángeles, y el economista Jeffrey Sachs (2008), director del Instituto de la Tierra de la Universidad de Columbia.
Pero no basta con el consenso científico para que se pase a la acción: el movimiento ciudadano ecologista juega aquí un papel fundamental. Es importante por ello mostrar hasta qué punto es injusta la acusación de "fundamentalismo" que se le imputa. Nos referiremos con este fin a la historia del movimiento ecologista para mostrar su estrecha vinculación con la comunidad científica y la racionalidad de sus planteamientos.

\section{El surgimiento del movimiento ecologista}

Rachel Carson es considerada hoy la "madre del movimiento ecologista" y merece la pena recordar aquí sus trabajos acerca de los efectos del DDT, porque son un buen ejemplo de cómo la comunidad científica y el incipiente movimiento ecologista abordaron los tópicos ambientales, muy lejos, como veremos, de todo "discurso oficial" y de cualquier fanatismo.

Es bien conocido que la utilización de productos de síntesis para combatir los insectos, plagas, malezas y hongos aumentó la productividad en un periodo - tras la Segunda Guerra Mundial - en el que un notable crecimiento de la población mundial lo exigía. Pero esta utilización de los productos químicos de síntesis, y en particular del DDT, fue denunciada a finales de los años 50 por Rachel Carson (1980) en su libro Primavera silenciosa (título que hace referencia a la desaparición de los pájaros), en el que daba abundantes y contrastadas pruebas de los efectos nocivos del DDT... lo que no impidió que fuera violentamente criticada y sufriera un acoso muy duro por parte de la industria química implicada, los políticos e incluso algunos científicos, que negaron valor a sus pruebas y le acusaron de estar contra un progreso "que permitía dar de comer a una población creciente y salvar así muchas vidas humanas".

Sin embargo, apenas 10 años más tarde se reconoció que Carson tenía razón y que el DDT y otros productos similares eran realmente un peligroso veneno, prohibiéndose su utilización en el mundo rico (aunque, desgraciadamente, se siguió utilizando durante bastante tiempo en los países en desarro1lo). La Comisión Mundial del Medio Ambiente y del Desarrollo (1988) acabó reconociendo que su uso constituye una amenaza para la salud humana, provocando desde malformaciones congénitas hasta cáncer, y siendo auténticos venenos para peces, mamíferos y pájaros. Por ello dichas sustancias, que se acumulan en los tejidos de los seres vivos, han llegado a ser denominadas, junto con otras igualmente tóxicas, "Contaminantes Orgánicos Persistentes" (COP). Y por esa misma razón ha surgido una "Química verde" que persigue reducir la contaminación mediante la búsqueda de productos que no atenten contra la salud o el ambiente y la puesta a punto de procesos que reduzcan o eliminen las sustancias peligrosas.

Lo que nos interesa destacar aquí es que la batalla contra el DDT fue dada por científicos como Rachel Carson en confluencia con grupos ciudadanos que fueron sensibles a sus llamadas de atención y argumentos. De hecho Rachel Carson es hoy recordada, ya lo hemos señalado, como "madre del movimiento ecologista" - por la enorme influencia que tuvo su libro en el surgimiento de grupos activistas, que reivindicaban 
la necesidad de la protección del medio ambiente- así como en los orígenes del denominado movimiento CTSA. Sin la acción de estos grupos de ciudadanos y ciudadanas con capacidad para comprender los argumentos de Carson, la prohibición se hubiera producido mucho más tarde, con efectos aún más devastadores. Conviene llamar la atención sobre la influencia de estos "activistas ilustrados" y su indudable participación en la toma de decisiones, al hacer suyo el principio de precaución y exigir controles rigurosos de los efectos del DDT, que acabaron convenciendo a la comunidad científica y, posteriormente, a los legisladores, obligando a su prohibición. Y conviene señalar también que algunos científicos, con un nivel de conocimientos sin duda muy superior al de esos ciudadanos, no supieron o quisieron ver inicialmente los peligros asociados al uso de plaguicidas.

Una situación similar se vivió en los años 70 con el uso de los compuestos fluorcarbonados y el hallazgo de que provocaban un peligroso adelgazamiento de la capa de ozono: gracias a los trabajos de científicos como Crutzen, Rowland y Molina y al apoyo del movimiento ecologista, que contribuyó a dar realce social a sus investigaciones, se logró en 1987 prohibir a tiempo su uso en el Protocolo de Montreal. Y no debemos olvidar que la primera reacción, sobre todo del mundo empresarial, fue poner en duda estos resultados: el presidente de DuPont, líder mundial en producción de CFC, calificó los estudios de "relatos de ciencia ficción", "montón de basura" "redomada insensatez"... (Sachs, 2008 p. 162). Crutzen, Rowland y Molina acabaron obteniendo el Premio Nobel de Química en 1995, pero mediante buscadores como Google podemos seguir encontrando "documentos" acerca del "Mito del agujero de Ozono", tan escasamente fiables como los que se refieren a "las mentiras del cambio climático".

Como puede apreciarse en estos y otros ejemplos -incluido el actual problema del incremento de los gases de efecto invernadero- el movimiento ecologista ha sido deudor y se ha hecho siempre eco del trabajo científico: su papel ha sido el de dar realce a investigaciones que no estaban recibiendo la atención y apoyo necesarios y acelerar así la toma en consideración de los problemas. Difícilmente se puede, pues, tildar al movimiento ecologista de practicar "un discurso de tono religioso que raya el fanatismo ecológico".

Sin duda podemos encontrar ejemplos de un tal discurso irracional, pero su presencia es muy minoritaria en el seno de dicho movimiento ecologista y, por supuesto, prácticamente nula en la comunidad científica. Y no debemos olvidar que es el conjunto de la comunidad científica la que ha acabado reconociendo la seriedad del problema del cambio climático o, mejor dicho, del cambio global (Duarte, 2006) al que la humanidad ha de hacer frente hoy.

\section{Del consenso científico al consenso social}

El mayor problema, sin embargo, es que el conjunto de la ciudadanía, sus representantes políticos y buena parte de los educadores, todavía no hemos comprendido la necesidad de actuar sin dilación. Estamos, por tanto, muy de acuerdo con las ideas propuestas en esta misma revista en su editorial de octubre de 2007 (Arjonilla y Gárriz, 2007) cuando refiriéndose a lo que podemos hacer los educadores plantea la necesidad de:

_ "... no propiciar la inacción al alarmar en vez de alertar"

- construir "una visión integral del mundo"

- concebir la crisis actual como una situación de "riesgo y oportunidad".

En la Cumbre de Valencia de noviembre de 2007, el Panel Intergubernamental del Cambio Climático (IPCC, 2007) presentó su informe a los delegados gubernamentales de 130 países. Un informe en el que destaca el espacio concedido a las medidas mitigadoras y la fundamentada conclusión de que todavía estamos a tiempo... pero que es urgente actuar.

Como señala Sachs (2008): "El del cambio climático es sin duda un problema soluble. De hecho ya hemos abordado con anterioridad un reto similar, si bien mucho más específico, con un éxito rotundo. Los avances en la lucha contra la desaparición del ozono estratosférico nos brinda ahora importantes lecciones".

No es, pues, haciéndonos eco de quienes tildan hoy de fundamentalistas a los científicos del IPCC (como se hizo antes con Carson o con Rowland y Molina, por no remontarnos a otros ejemplos menos recientes en la historia de la ciencia y su batalla contra auténticos fundamentalismos) como lograremos avanzar en la compresión de los problemas, sus causas y medidas a adoptar. Nuestra obligación como educadores científicos es manejar información contrastada, procedente de auténticas revistas científicas, no difundir opiniones peregrinas y a menudo interesadas (es decir, literalmente pagadas por compañías petroliferas, mineras, etc., como se ha documentado también fehacientemente) aparecidas en unos media más atentos a la "noticia" con capacidad de llamar la atención que al rigor científico.

Nuestro papel es, en definitiva, contribuir a la necesaria implicación ciudadana para que sean atendidos los hallazgos científicos y se empiecen a diseñar y poner en práctica las medidas científico-tecnológicas, educativas y politicas que hagan posible un futuro sostenible.

\section{Referencias bibliográficas}

Arjonilla, Elia y Gárriz, Andoni, Cambio climático. Lo que podemos hacer los educadores, Educ. quim., 18(4) 251256, 2007.

Carson, Rachel, Primavera silenciosa, Barcelona: Grijalbo, 1980.

Comisión Mundial del Medio Ambiente y del Desarrollo, Nuestro Futuro Común. Madrid: Alianza, 1988.

Diamond, Jared, Colapso, Barcelona: Debate, 2006.

Duarte, Carlos (coordinador), Cambio Global. Impacto de la actividad humana sobre el sistema Tierra. Madrid: CSIC (Consejo Superior de Investigaciones Científicas), 2006.

Garritz, Andoni y Arjonilla, Elia, El cambio climático a través del discurso religioso y del discurso políticamente incorrecto, Educ. quím., 19(2), 90-93, 2008. 
Intergovernmental Panel on Climate Change (IPCC), Working Group III Report: Mitigation of Climate Change, in: Climate Change 2007 IPCC, Fourth Assessment Report (AR4). Accesible en: http://www.ipcc.ch/.

Lomborg, Bjorn, The skeptical environmentalist. Measuring the Real State of the World, Cambridge: Cambridge University Press, 2001. (Existe traducción al español en Espasa-Calpe, 2005).

Sachs, Jeffrey, Economía para un planeta abarrotado, Barcelona: Debate, 2008 (Edición en inglés del mismo año titulada: Common Wealth: Economics for a Crowded Planet).

Vilches, Amparo, Gil Pérez, Daniel, Toscano, Juan Carlos y
Macías, Óscar, 21 Temas de acción clave que ofrecen una documentación puesta regularmente al dia acerca de los problemas estrechamente vinculados a los que la humanidad ha de hacer frente hoy (como, entre otros, "Cambio climático", "Contaminación sin fronteras", "Biodiversidad", etc.), sus causas y medidas necesarias para hacerles frente, 2008. Accesibles en la web de la Década de la educación por un futuro sostenible (www.oei.es/decada).

White, Jr., Lynn, The historical Roots of Our Ecologic Crisis, Science, New Series, 155 (3767) March 10, 1203-1207, 1967. Citado por Garritz y Arjonilla (2008).

\title{
VIII Congreso InTERnACIONAL SOBRE INVESTIGACIÓN EN DidÁCTICA DE LAS Ciencias Experimentales
}

\author{
Barcelona, del 7 al 10 de septiembre de 2009
}

Del 7 al 10 de septiembre de 2009 tendrá lugar en Barcelona el VIII Congreso Internacional sobre Investigación en Didáctica de las Ciencias, organizado por la revista Enseñanza de las Ciencias. L'Institut de Ciències de l'Educació de la Universitat Autònoma de Barcelona y el Vicerectorat d'Investigació de la Universitat de València, como editores de la revista, os invitan a participar. En esta edición el tema central es:

\section{Enseñanza de las ciencias en un mundo en transformación}

La sede es el CosmoCaixa de Barcelona. El periodo de envío de propuestas de comunicación se inicia el 15 de noviembre y estará abierto hasta el 19 de enero. En lo que se refiere a la inscripción estará abierta hasta el 31 de mayo. Todos los trámites pueden realizarse a través de la página web del Congreso

\section{http://ensciencias.uab.es/congreso2009/}

